Document downloaded from:

http://hdl.handle.net/10251/170285

This paper must be cited as:

Merello, P.; De La Poza, E.; Jódar Sánchez, LA. (2020). Explaining shopping behavior in a market economy country: A short-term mathematical model applied to the case of Spain. Mathematical Methods in the Applied Sciences. 43(14):8089-8104. https://doi.org/10.1002/mma.6072

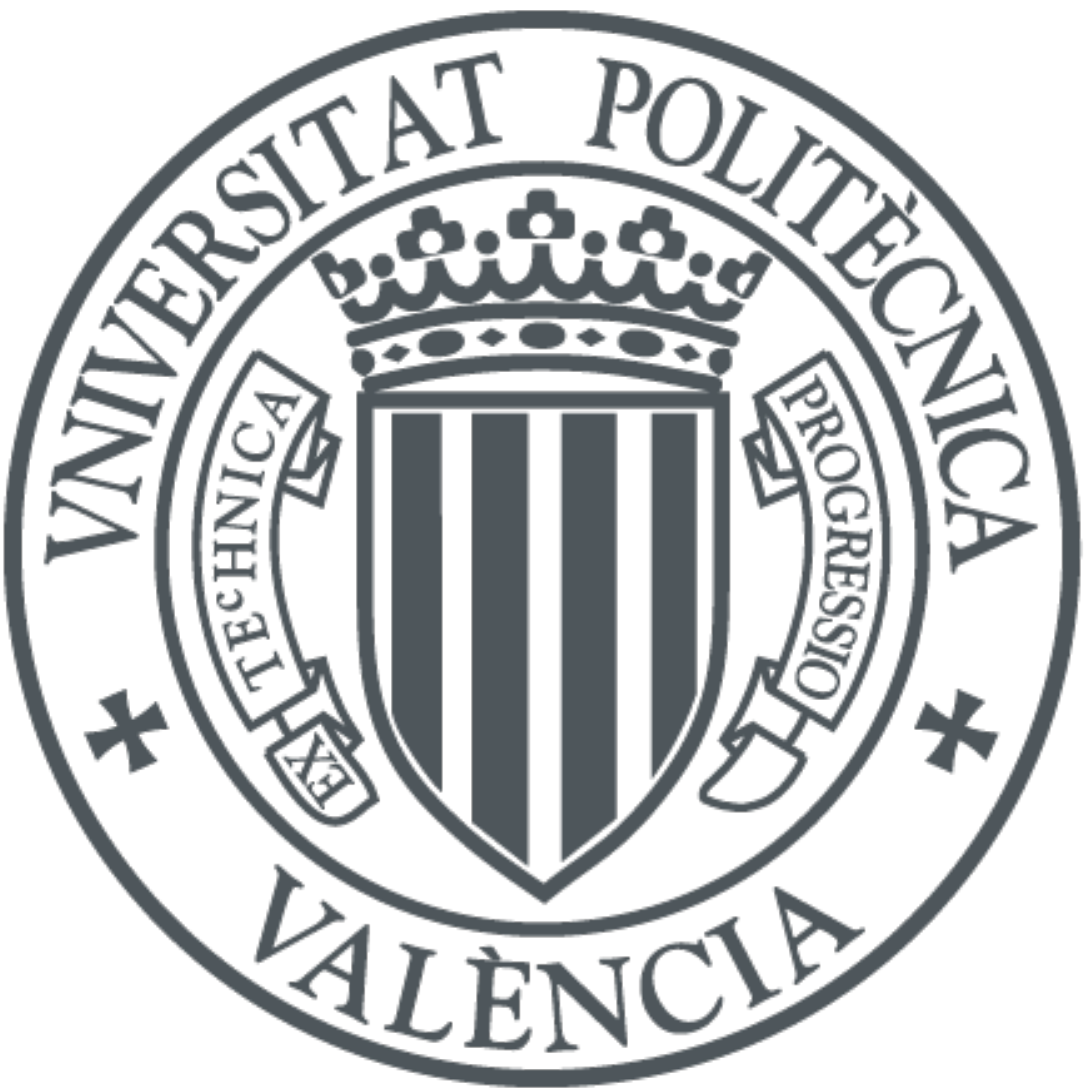

The final publication is available at https://doi.org/10.1002/mma.6072

Copyright John Wiley \& Sons

Additional Information 


\title{
Explaining shopping behavior in a market economy country: a short- term mathematical model applied to the case of Spain
}

\author{
A mathematical model of shopping behavior \\ Paloma Merello ${ }^{1, *}$, Elena de la Poza ${ }^{2}$ and Lucas Jódar ${ }^{3}$. \\ ${ }^{1}$ Department of Accounting, University of Valencia, Valencia, Spain. ${ }^{2}$ Center for \\ Economic Engineering, Universitat Politècnica de València, Valencia, Spain. ${ }^{3}$ Institute \\ for Multidisciplinary Mathematics, Universitat Politècnica de València, Valencia, \\ Spain. \\ *corresponding author: paloma.merello@uv.es; Avd Naranjos, s/n, 46071, Valencia, \\ Spain.
}

Acknowledgements: This work has been partially supported by the Ministerio de Ciencia, Innovación y Universidades, Spanish grant MTM2017-89664-P.

Abstract: In recent decades, pathological consumption has become a growing behavioral misbehavior. Impulsive consumption is governed by two internal behavioral mechanisms that respond fundamentally to the hedonism or Pascal effect, and to the emulation or Veblen effect. Today's development of technology acts as a catalyst of consumption by increasing access and availability to products, as well as the advertisement impact. This paper presents a compartmental discrete matrix mathematical model that allows shortterm estimates of ordinary, impulsive and pathological buyers in Spain in three different economic scenarios. The results show that impulsive and pathological buyers will increase in all the economic scenarios. Notable differences in the number of ordinary buyers are found for the group aged over 65 years.

Keywords: Impulsive consumption, human behavior, simulation, bilateral linear matrix difference equation, compartmental model. 


\section{Introduction}

The 21 st century is the era of addictions. Western consumer societies are characterized by values of freedom, autonomy and choice associated with the emergence and spread of consumerism [1]. However in the opposite direction to these liberal values we find that the consumption desire in current societies can become a need when individuals lose control and autonomy, and accordingly lack choice. Then comes a rise in the so-called 'addictive' behaviors [2].

Apart from classic addictions linked to substance abuse of alcohol or drugs, many others have emerged in recent years: addiction to technology, social media, mobile phone, video games, Internet, online gambling, etc. [3].

Furthermore, technology itself is a vehicle that multiplies the magnitude of these addictions. An addiction such as "addictive consumption" has been hidden given its social acceptance and marketing. Thus shopping is encouraged because it accelerates the economic growth of market economy countries, but is also known as "retail therapy" and prescribes to abate negative emotions [4].

We understand shopping as the process of seeking products that you did not know you wanted [5]; when desire becomes an uncontrolled need, compulsive behavior emerges. Then shopping becomes an oniomania.

Shopping might be motivated by several emotional inputs, such as satisfaction (Pascal effect), self-esteem improvement [6,7,8], prestige (Veblen effect), emotional recovery (snob effect) and social contagion (bandwagon effect) [9].

Thus consumer behavior is hedonistic when explained by the self-satisfaction experienced when shopping, in addition to the pleasure that derives from the product's attributes $[10,11,12]$. There is a second type of consumption, the conspicuous one. It is explained by those consumers who emulate upper classes by purchasing similar products $[13,14]$.

It is understood that human behavior is dynamic, which means individuals' habits and characteristics can modify over time to cover different factors that are driven especially by our emotions instead of by reason [15]. In addition, individual human behavior shows common patterns, which means that it can be predictable in aggregate terms [16] given its mimetic component [17]. Thus individuals imitate their peers by looking to emulate them, but also influence others' behavior (contagion effect) $[17,18,19,20]$. These principles, which come from philosophy, sociology, psychology and neurology, allow us to split the population into compartments by preserving homogeneity. Yet despite free will, populations are subject to dynamic changes due to emotional impact, the economy, age, social emulation, technology, or a combination of all these factors to consumers' behavior. For sake of reliability, the study period should not be long because economy and demography are time-sensitive.

The primary goal of this work is to study the aggregate patterns of consumers' behavior by identifying and quantifying the factors that explain it. For this purpose, we provide a dynamic population model to explain shopping behavior by supporting the view of [21].

The proposed compartment model [22] classifies and quantifies shopper populations into Spain into three groups: rational consumers or consumers who plan their shopping; 
impulsive consumers who overconsume; pathological consumers who show compulsive shopping behavior.

This paper may be regarded as an important improvement to [23], where a compartment discrete mathematical model was developed for the first time. However in this previous work, shoppers' age (the second compartment indicator here) [24] or important factors that accelerate shopping such as e-commerce, [25], and the Pascal and Veblen effects were not considered [26], but others like religiosity proved capable of braking unplanned shopping [27].

Shopping power varies with age [28] and is a relevant variable to explain shopping behavior not only because of the economic influence (young people have less income available), but also because of the bandwagon effect as youths show a higher contagion propensity when attempting to emulate their icons [29, 30, 31].

The approach employed herein has been recently considered when dealing with other social problems [32] by following the thinking of Michael Faraday: what is not measured is not controlled and cannot be improved [33].

For the first time, we develop a behavioral mathematical bilateral matrix difference model to model consumers' behavioral dynamics to estimate the short-term evolution of different consumer subpopulations by age groups under different economic scenarios. Total impulsive and pathological buyers will increase in all the economic scenarios with differences between age groups, especially in the number of ordinary buyers found for the group over 65 years.

The paper is organized as follows: Section 2 introduces the algebraic preliminaries. Section 3 provides details of the hypotheses. Section 4 introduce the parameters definition and the quantification of transit coefficients. Section 5 deals with the model building, the mathematical formulation in terms of a linear bilateral matrix difference equations. Section 5 shows that by considering the matrix unknown $W(t)$ of the different subpopulations, dynamic change can be written as a dynamic model $W(t+1))=$ $f(W(t))$. This equation is explicitly solved and the initial value condition $W(0)$ is computed. Section 6 provides the results and the simulations of the model with a variety of sensitive parameters. Section 7 includes the study conclusions.

\section{Algebraic Preliminaries}

For sake of clarity to present the paper, we recall some notations and results of the matrix calculus related to the Kronecker product of matrices, which are used later. If $A$ is a matrix in $\mathbb{R}^{m \times n}$ and $B$ is a matrix in $\mathbb{R}^{p \times q}$, then the Kronecker product of $A$ and $B$, denoted by $A \otimes B$, is the block matrix in $\mathbb{R}^{m p \times n q}$ defined by [34a],

$$
A \otimes B=\left(\begin{array}{cccc}
a_{11} B & a_{12} B & \cdots & a_{1 n} B \\
\vdots & \vdots & & \vdots \\
a_{m 1} B & a_{m 2} B & \cdots & a_{m n} B
\end{array}\right)
$$

If $A \in \mathbb{R}^{m \times n}$, then the operation column vector denoted by vec: $\mathbb{R}^{m \times n} \rightarrow \mathbb{R}^{m n}$ and acting in $A$ gives the vector in the $\mathbb{R}^{m n}$ listing and orders the columns of $A$, as follows: 


$$
\operatorname{vec}(A)=\left(\begin{array}{c}
a_{11} \\
\vdots \\
a_{m 1} \\
a_{12} \\
\vdots \\
a_{m 2} \\
\vdots \\
a_{1 n} \\
\vdots \\
a_{m n}
\end{array}\right) \in \mathbb{R}^{m n}
$$

If $A, Y, B$ are matrices in $\mathbb{R}^{m \times n}, \mathbb{R}^{n \times p}$ and $\mathbb{R}^{p \times q}$, respectively, by [34b] we find that:

$$
v c(A Y B)=\left(B^{T} \otimes A\right) \text { vec } Y
$$

where $B^{T}$ denotes the transposed matrix of $B$.

If $\left\{\lambda_{i}\right\}$ and $\left\{x_{i}\right\}$ are the eigenvalues, and the corresponding eigenvectors for $A$ and $\left\{\mu_{j}\right\}$ and $\left\{y_{j}\right\}$ are the eigenvalues and the corresponding eigenvectors for $B$, then

$A \otimes B$

has eigenvalues $\left\{\lambda_{i} \mu_{j}\right\}$ with corresponding eigenvectors $\left\{x_{i} \otimes y_{j}\right\}$; see [34c].

\section{Literature review, definition of subpopulations and hypotheses development}

We go on to define the three possible consumer subpopulations $(N, S, A)$ based on their emotional dependence on shopping.

On the one hand, ordinary consumers $(N)$ are defined as those shoppers who follow a rational and planned purchase behavior. According to today's consumption culture, we assume that only those consumers forced by beliefs or economic needs will form part of this subpopulation. Thus devoted religious people (religious practitioners attending religious meetings once a week or more often) [27], people at risk of poverty (according to the poverty risk rate), the long-term unemployed, but also $50 \%$ of the retired population, are assumed to be rational buyers, [35].

On the other hand, impulsive consumers $(S)$ are those who spontaneously and immediately lose control of shopping when their desire for a specific item outweighs their willpower to resist it $[36,37,38]$, which is mostly driven externally (e.g. advertisement). Finally, pathological consumers $(A)$ are identified as being the top disordered consumers, characterized by not only inappropriate buying behavior driven by internal needs, but also by repetitive problematic spending patterns that interfere with social, work or role functioning $[36,39,40]$. Investigation tools have been developed to diagnose the problem, such as interviews [41] and questionnaires [42, 43].

In order to construct a mathematical model and to estimate the transition coefficients, some hypotheses $(\mathrm{H})$ need to be set out.

H1: Overconsumption is driven mainly by the Veblen and Pascal factors.

The Veblen effect [19], also known as conspicuous consumption, is an externally socialdriven consumption with which consumers emulate upper classes through their purchases $[13,14,44,45,46]$. 
The Pascal effect [10], or hedonistic consumption, is characterized by a more internal projection by which the consumer is self-satisfied thanks to the act of consuming or the pleasures derived from the product $[11,12,47,48,49]$. Both effects are assumed to be universal and independent of a buyer's age and gender.

The factor that drives consumption depends on the specific characteristics of the consumer and his/her environment. Luxury products are a particular case of hedonistic and conspicuous consumption as products from the luxury industry become experiential. This experience is both individual and social [50] as it provides a hedonistic value and builds a social status around its differentiation.

$\mathrm{H} 2$ : "One jump principle" is based on the fact that humans are creatures of habits and behavior changes need time $[17,19]$, which means the transition among subpopulations, occurs consecutively; thus an individual from subpopulation $N$ can only transit to $S$, and one from subpopulation $A$ can only transit/come to/from $S$ from one semester to the next one, as Figure 1 shows. One-jump principle is an accepted underlying hypothesis in dynamic behavioral models such us [23] or [32].

[Figure 1 about here]

H3: E-commerce is a catalyst for the Veblen and Pascal effects. Online shopping favors consumption as stores are open $24 \mathrm{~h}$ a day/7 days a week. The consumer receives an external stimulus of the desired products selected specially for his/her profile. Literature suggests that addiction symptoms are related to technology [51], specifically Qasem (2019) [52] suggests shopping addiction as a potential negative outcome of technostress.

H4: Those consumers who have no surplus saving (precariat) are not predisposed to overconsumption. According to this statement, immigrants who send money to their origin countries are, by definition, not predisposed to overconsumption $[53,54,55]$.

H5: Devout religious people are not predisposed to hedonist or conspicuous consumption $[56,57]$. Hence they belong to the ordinary shopper subpopulation $(N)$ and are not culturally susceptible to transit to impulsive shoppers $(S)$.

H6: Impulsive $(S)$ to pathlogical shopper $(A)$ transits are more complex and require an external catalyst event with a strong emotional impact [23], while transits from the ordinary shopper subpopulation (N) to Impulsive (S) are affected only by the personal characteristics of the buyers and their habits [26].

Finally, age has been identified as a determinant factor for developing a pathological consumption disorder [36]. Age inversely correlates with the disorder and indicates that younger people are more prone to manifest the pathology.

In this work we identify and classify the Spanish population according to their level of consumption by paying special attention to differences in line with age. So let's define the three possible consumer subpopulations $\left(N_{j}, S_{j}, A_{j}\right)$ based on their emotional dependence and habits on shopping [26], where $j=1,2,3,4$ refers to the age groups 
comprising individuals aged within the range [16,25] for $j=1,[26,35]$ for $j=2$, $[36,64]$ for $j=3$ and 65 and more for $j=4$.

H7: The dynamics of consumption are affected by cultural and educational factors, which are intrinsically linked to age. In addition, age is a factor that is significantly positively related to fear and prudence [58]. Hence, we define the "retirement effect" as the fact that people after retirement become more concerned about their health and economic problems than with their self-satisfaction $[56,59]$. This implies that a proportion of impulsive shoppers $\left(S_{3}\right)$ transits to ordinary shoppers $\left(N_{3}\right)$ when they retire (on average at 65 years).

\section{Parameters definition and estimation}

The considered demographic variables are birth rate $(\sigma)$ and death rate $\left(d_{j}\right)$ for each $j$. Birth rate includes the proportion of all new consumers over the total population who enter the model (they reach the age of 16 years). These parameters are assumed constant in the short term.

New incomers are distributed among the three consumer subpopulations for $j=1$ by considering the prevalence rate of impulsive $(S)$ and pathological consumption $(A)$ in high school students when the present study commenced: hence they equal $S_{1,0}$ and $A_{1,0}$, respectively.

Migratory balance is considered a possible entry/exit of each subpopulation. Parameter $i_{j}$ denotes migratory balance (immigrants minus emigrants) in Spain by age group $j$ [60].

According to $\mathrm{H} 4$, the immigrants who arrive in Spain in a precarious situation are considered rational buyers. Let's define $\tau$ as the percentage of immigrants who come from origin countries in a worse economic situation (compared to Spain), send money to their relatives and have no surplus to overconsume. The average data for 2016 and 2017 evidence that $\tau=0.81 \times 0.679=0.55$. Moreover, $81 \%$ of immigrants do not have surplus money for either saving or spending, obtained as the average of those who send money to their relatives $(68 \%,[61]$ and precarious immigrants $(94 \%,[62])$. Besides, $67.90 \%$ of immigrants in 2016 and 2017 came from countries where the economic situation was worse than in Spain [62]. Therefore, those precarious immigrants who arrive in Spain $\left(i_{j} \tau\right)$ enter as ordinary buyers $\left(N_{j}\right)$. Non precarious immigrants are distributed among the different subpopulations according to the initial prevalence rates.

As regards the retirement effect $(\mathrm{H} 7)$, let's define $\propto$ as the proportion of impulsive consumers aged up to 64 years who transit to rational consumers when they reach the age of 65 years and retire. The main concerns of Spanish retirees [59] are pensions (60\%), loneliness (46\%) and health (39\%). Moreover, 59\% admit that one of the worst things about retirement is adjusting to a reduced budget [60]. Therefore, we assume that $59 \%$ of the impulsive consumers move to rational consumers when they retire $(\alpha=0.59)$.

The estimated values of the previous coefficients for each $j$ and the absolute demographic balance are shown in Table 1, considered a basis for the calculus of the total Spanish population aged over 16 years in $2016(t=0)$. 
[Table 1 about here]

The transition among age groups addresses demographic factors (see Figure 2).

[Figure 2 about here]

\subsection{Transits from Ordinary (N) to Impulsive (S) shoppers}

Let $V$ be the percentage of consumers affected by the Veblen effect. Palma et al. [63] found that $9.26 \%$ of consumers are "prestige lovers" and believe that status can be achieved even with relatively inexpensive purchases. Then $V=0.0926$.

Let $P$ be the percentage of consumers affected by the Pascal effect. The hedonistic spending of consumers for themselves is estimated at $47.55 \%$ and the hedonistic spending on purchases for others has been found to be $66.67 \%$ [12]. As users normally spend more on themselves than on others, we assume that $50 \%$ of consumers make hedonistic purchases $(P=0.5)$.

With H3, we state that e-commerce is understood as a catalyst of the Veblen and Pascal effects. In addition, compulsive and non compulsive consumers did not differ in the types of consumer goods they purchased, but in the frequency with which consumer goods were purchased [64]. Lam and Lam (2017) [65] have evidenced that those buying on the Internet more than once a week are at a significantly increasing risk of becoming problematic shoppers.

We assume that those ordinary consumers who buy on the Internet more than 3 times a month $\left(\varepsilon_{j}\right)$ are at risk of becoming impulsive buyers (excluding those new consumers at risk of poverty). Thus let $V_{j, t}^{\prime}=V\left(\varepsilon_{j}-\left(\right.\right.$ Poverty $_{\text {rate }_{j, t+1}}-$ Poverty $\left.\left._{\text {rate }_{j, t}}\right)\right)$ and $P_{j, t}^{\prime}=P\left(\varepsilon_{j}-\left(\right.\right.$ Poverty $_{\text {rate }}{ }_{j, t+1}-$ Poverty $\left.\left._{\text {rate }_{j, t}}\right)\right)$.

The values of Poverty rate $_{j, t}$ and $\varepsilon_{j}$ are obtained from [62]. Note that we consider $\varepsilon_{j}$ constant in the short term (not dependent on $t$ ) because the evolution of $\varepsilon_{j}$ over time was analyzed and no trend was found $\left(\varepsilon_{1}=0.0384, \varepsilon_{2}=0.0568, \varepsilon_{3}=0.0146\right.$ and $\varepsilon_{4}=$ 0.0032 ). Poverty risk rates depend on $j$ and take the values shown in Table 2 for semester $t=0$ and $t=2$, respectively.

[Table 2 about here]

Based on $\mathrm{H} 4$ and $\mathrm{H} 5$, devout religious and precarious immigrants are not susceptible to transit to impulsive buyers. Let's assign $N^{\top}{ }_{j, t}$ to the ordinary buyers susceptible to become impulsive buyers, obtained as,

$$
N^{-}{ }_{j, t}=N_{j, t}-R_{j}\left(N_{j, t}\right)-\tau^{\prime} \times x\left(N_{j, t}\right),
$$


where $x$ is the proportion of non Spaniard inhabitants of the total population in Spain, $R_{j}$ is the percentage of devoted religious people who will not culturally become impulsive shoppers and $\tau^{\prime}$ is the percentage of foreigners living in Spain who come from countries whose economic situation is worse than that of Spain, send money to their relatives and have no savings to overconsume.

Note that as age is a determining factor for developing the disordered consumption behavior, we assumed that $25 \%$ of devoted religious young people are susceptible to transit to a higher consumption level as their beliefs are still immature and less rooted.

The estimation of $\tau^{\prime}$ is lower than $\tau$ as the proportion of foreigners living in Spain who come from countries with a worse economic situation $(54.46 \%)$ is lower than the proportion of new immigrants arriving $(67.90 \%)$. Thus $\tau^{\prime}=0.81 \times 0.5446=0.4411$.

\subsection{Transits from Impulsive (S) to Pathological (A) shoppers}

The Veblen $(V)$ and Pascal $(P)$ coefficients are defined and take values as for transits from ordinary $(N)$ to impulsive $(S)$ shoppers. However as H6 states, transits from impulsive to pathological buyers are complex and need an external trigger.

Let's define $E_{j, t}$ as the parameter that measures the economic distress effect for each $j$ in semester $t$. Hence we assume that a consumer who suffers anxiety or depression $\left(\varphi_{j}\right)$, and also economic distress (proxied by Poverty rate $_{t+1}-$ Poverty $_{\text {rate }_{t}}$, for Poverty $_{\text {rate }_{t+1}}>$ Poverty $_{\text {rate }_{t}}$ ), is susceptible to become a pathological consumer. However, only those who are hedonic $(P)$ or conspicuous $(V)$ shoppers will transit as they will overcome distress by receiving support from purchasing. Hence $E_{j, t}=\varphi_{j} \times$ $\left(\right.$ Poverty $_{\text {rate }_{t+1}}-$ Poverty $\left._{\text {rate }_{t}}\right)$.

Note that the anxiety or depression statistics for $j$ are as follows [66, 67], $\varphi_{1}=0.141$, $\varphi_{2}=0.331, \varphi_{3}=0.278$ and $\varphi_{4}=0.277$.

Let's define $u_{j}$ as the parameter that measures the emotional distress effect for each $j$. Hence we assume that those consumers suffering anxiety or depression $\left(\varphi_{j}\right)$ from getting divorced (a proxy of emotional distress) are susceptible to become pathological consumers. However, only those who are hedonic $(P)$ or conspicuous $(V)$ consumers will transit as they will overcome the distress from receiving support from shopping.

Every year, the percentage of the total Spanish population that ends their marriage for each $j$ [62] is $0.014 \%$ for $j=1,0.201 \%$ for $j=2$, and $0.411 \%$ and $0.063 \%$ for $j=3,4$, respectively. Hence $u_{j}$ takes the following semester values, $u_{1}=\frac{0.00014 \times 0.141}{2}=$ $9.64 \times 10^{-6}, u_{2}=\frac{0.00201 \times 0.331}{2}=0.00033, u_{3}=\frac{0.00411 \times 0.278}{2}=0.00057$ and $u_{4}=$ $\frac{0.00063 \times 0.277}{2}=8.71 \times 10^{-5}$.

Finally, we assume the same therapy recovery rate $(r)$ for pathological shoppers as in [23, 68] because the recognition of behavioral disorder continues without having substantially increased. We adapt the value of the parameters to semi-annual transits as follows.

Let's define $r$ as the rate at which a pathological shopper goes to therapy and becomes an ordinary shopper. Thus $r=0.0035$ semester $^{-1}$. This parameter is estimated by taking 
into account: (i) the percentage of pathological shoppers who begin therapy every year $(0.35 \%)$; (ii) the average percentage of successful therapy programs $(50 \%)$; (iii) the median therapy duration, 12 weeks ( 3 months). Then we obtain $r=0.0035 \times 0.5 \times 2$.

\section{Model and initial subpopulations}

\subsection{Compartmental difference equations model}

According to the subpopulations definition, let $B_{t}$ be the total population of consumers in Spain older than 16 years. Thus $B_{t=} N_{t}+S_{t}+A_{t}$, where

$$
\begin{gathered}
N_{t=} N_{1, t}+N_{2, t}+N_{3, t}+N_{4, t}, \\
S_{t=} S_{1, t}+S_{2, t}+S_{3, t}+S_{4, t}, \\
A_{t=} A_{1, t}+A_{2, t}+A_{3, t}+A_{4, t} .
\end{gathered}
$$

The compartmental difference equations model for the shopping behavior dynamics in Spain is as follows ( $t$ in semesters) according to age groups $(j)$

$$
\begin{aligned}
& N_{1, t+1=} N_{1, t}+87,214-\frac{1}{20} N_{1, t}-\left(V_{1, t}^{\prime}+P_{1, t}^{\prime}\right) N_{1, t}^{\prime}+r A_{1, t} \\
& S_{1, t+1=} S_{1, t}+103,696-\frac{1}{20} S_{1, t}+\frac{19}{20}\left(V^{\prime}{ }_{1, t}+P^{\prime}{ }_{1, t}\right) N^{\prime}{ }_{1, t}-(P+V) u_{1} S_{1, t}-\left(P_{t}+V_{t}\right) E_{1, t} S_{1, t} \\
& A_{1, t+1=} A_{1, t}+41,167-\frac{1}{20} A_{1, t}+\frac{19}{20}(P+V) u_{1} S_{1, t}+\frac{19}{20}(P+V) E_{1, t} S_{1, t}-r A_{1, t} \\
& N_{2, t+1=} N_{2, t}+1,498+\frac{1}{20} N_{1, t}-\frac{1}{20} N_{2, t}-\left(V_{2, t}^{\prime}+P_{2, t}^{\prime}\right) N_{2, t}^{\prime}+r A_{2, t} \\
& S_{2, t+1=} S_{2, t}+56+\frac{1}{20} S_{1, t}-\frac{1}{20} S_{2, t}+\frac{19}{20}\left(V^{\prime}{ }_{2, t}+P^{\prime}{ }_{2, t}\right) N^{\prime}{ }_{2, t}-(P+V) u_{2} S_{2, t}-(P \\
& +V) E_{2, t} S_{2, t}+\frac{1}{20}\left(V_{1, t}^{\prime}+P_{1, t}^{\prime}\right) N^{\prime}{ }_{1, t} \\
& A_{2, t+1=} A_{2, t}+21+\frac{1}{20} A_{1, t}-\frac{1}{20} A_{2, t}+\frac{19}{20}(P+V) u_{2} S_{2, t}+\frac{19}{20}(P+V) E_{2, t} S_{2, t}+\frac{1}{20}(P \\
& +V) u_{1} S_{1, t}+\frac{1}{20}(P+V) E_{1, t} S_{1, t}-r A_{2, t} \\
& N_{3, t+1}=N_{3, t}-15,519+\frac{1}{20} N_{2, t}-\frac{1}{58} N_{3, t}-\left(V_{3, t}^{\prime}+P_{3, t}^{\prime}\right) N_{3, t}^{\prime}+r A_{3, t} \\
& S_{3, t+1=} S_{3, t}-19,333+\frac{1}{20} S_{2, t}-\frac{1}{58} S_{3, t}+\frac{57}{58}\left(V^{\prime}{ }_{3, t}+P^{\prime}{ }_{3, t}\right) N^{\prime}{ }_{3, t}-(P+V) u_{3} S_{3, t}-(P \\
& +V) E_{3, t} S_{3, t}+\frac{1}{20}\left(V_{2, t}^{\prime}+P_{2, t}^{\prime}\right) N_{2, t}^{\prime} \\
& A_{3, t+1}=A_{3, t}-2,652+\frac{1}{20} A_{2, t}-\frac{1}{58} A_{3, t}+\frac{57}{58}(P+V) u_{3} S_{3, t}+\frac{57}{58}(P+V) E_{3, t} S_{3, t}+\frac{1}{20}(P \\
& +V) u_{2} S_{2, t}+\frac{1}{20}(P+V) E_{2, t} S_{2, t}-r A_{3, t}
\end{aligned}
$$




$$
\begin{gathered}
N_{4, t+1=} N_{4, t}-307,206+\frac{1}{58} N_{3, t}+\alpha \frac{1}{58} S_{3, t}-\left(V_{4, t}^{\prime}+P_{4, t}^{\prime}\right) N_{4, t}^{\prime}+r A_{4, t} \\
S_{4, t+1=} S_{4, t}-121,811+(1-\alpha) \frac{1}{58} S_{3, t}+\left(V_{4, t}^{\prime}+P_{4, t}^{\prime}\right) N^{\prime}{ }_{4, t}-(P+V) u_{4} S_{4, t}-(P \\
+V) E_{4, t} S_{4, t}+\frac{1}{58}\left(V^{\prime}{ }_{3, t}+P^{\prime}{ }_{3, t}\right) N^{\prime}{ }_{3, t} \\
A_{4, t+1=} A_{4, t}-15,097+\frac{1}{58} A_{3, t}+(P+V) u_{4} S_{4, t}+(P+V) E_{4, t} S_{4, t}+\frac{1}{58}(P+V) u_{3} S_{3, t} \\
+\frac{1}{58}(P+V) E_{3, t} S_{3, t}-r A_{4, t}
\end{gathered}
$$

Let's define $W(t)$ as the matrix unknown of the model, including all the subpopulations per age at time $t$, as:

$$
W(t)=\left(\begin{array}{lll}
N_{1, t} & S_{1, t} & A_{1, t} \\
N_{2, t} & S_{2, t} & A_{2, t} \\
N_{3, t} & S_{3, t} & A_{3, t} \\
N_{4, t} & S_{4, t} & A_{4, t}
\end{array}\right)
$$

For sake of convenience, let's introduce coefficients $\beta_{i}$ and $\beta_{r}$ by taking the values

$$
\begin{aligned}
& \beta_{i}=\left\{\begin{array}{c}
\frac{19}{20}, i=1,2, \\
\frac{57}{58}, i=3, \\
1, i=4,
\end{array}\right. \\
& \beta_{r}=\left\{\begin{array}{c}
\frac{1}{20}, r=1,2, \\
\frac{1}{58}, r=3 .
\end{array}\right.
\end{aligned}
$$

Note that with matrices $A_{i}(t)=\left(a_{p q}^{i}(t)\right) \in \mathbb{R}^{3 \times 3}, \quad B_{i}=\left(b_{p q}^{i}\right) \in \mathbb{R}^{4 \times 4}, C_{r}(t)=$ $\left(c_{p q}^{r}(t)\right) \in \mathbb{R}^{3 \times 3}$, and $D_{r}=\left(d_{p q}^{r}\right) \in \mathbb{R}^{4 \times 4}$, which are defined below, we show that $W(t+1)$ depends on $W(t)$ throughout the bilateral matrix equation in this form:

$$
W(t+1)=\sum_{i=1}^{4} A_{i}(t) W(t) B_{i}+\sum_{r=1}^{3} C_{r}(t) W(t) D_{r}+M
$$

where

$$
\begin{gathered}
a_{11}^{i}(t)=\beta_{i}+\left(-1+R_{i}+\tau^{\prime} x\right)\left(V^{-}{ }_{i, t}+P^{-}{ }_{i, t}\right) ; a_{13}^{i}(t)=r ; \\
a_{21}^{i}(t)=\beta_{i}\left(1-R_{i}-\tau^{\prime} x\right)\left(V^{-}{ }_{i, t}+P^{-}{ }_{i, t}\right) ; a_{22}^{i}(t)=\beta_{i}-\left(u_{i}+E_{i, t}\right)(P+V) ;
\end{gathered}
$$




$$
\begin{gathered}
a_{32}^{i}(t)=\beta_{i}\left(u_{i}+E_{i, t}\right)(P+V) ; a_{33}^{i}(t)=\beta_{i}-r ; \\
b_{p q}^{i}=\left\{\begin{array}{l}
1, p=q=i \\
0, \text { otherwise } ;
\end{array}\right. \\
c_{11}^{r}(t)=c_{33}^{r}(t)=\beta_{r} ; c_{12}^{r}(t)=\left\{\begin{array}{l}
0, r=1,2, \\
\frac{\alpha}{58}, r=3 ;
\end{array}\right. \\
c_{21}^{r}(t)=\beta_{r}\left(1-R_{r}-\tau^{\prime} x\right)\left(V_{r, t}^{-}+P^{-}{ }_{r, t}\right) ; c_{22}^{r}(t)\left\{\begin{array}{c}
\beta_{r}, r=1,2, \\
\beta_{r}(1-\propto), r=3
\end{array} ;\right. \\
c_{32}^{r}(t)=\beta_{r}\left(u_{r}+E_{r, t}\right)(P+V) ; \\
d_{p q}^{r}=\left\{\begin{array}{c}
1, p=1+r \text { and } q=r ; \\
0, \text { otherwise }
\end{array}\right.
\end{gathered}
$$

and $M$ is the demographic independent matrix given by

$$
M=\operatorname{vec}^{-1}(m)=\left(\begin{array}{ccc}
87214 & 103696 & 41167 \\
1498 & 56 & 21 \\
-15519 & -19333 & -2652 \\
-307206 & -121811 & -15097
\end{array}\right)
$$

Note that using the vector operation and property (2) of Section 2, we can write matrix equation (4), which can be transformed into the linear vector form:

$$
w(t+1)=G(t) w(t)+m
$$

where

$$
\left.\begin{array}{r}
w(t)=\operatorname{vec}(W(t)) ; \\
G(t)=\sum_{i=1}^{4} A_{i}(t) \otimes B_{i}+\sum_{r=1}^{3} C_{r}(t) \otimes D_{r} .
\end{array}\right\}
$$

From (5) and (6), we obtain:

$$
\begin{gathered}
w(t+2)=G(t+1) w(t+1)+m=G(t+1) G(t) w(t)+G(t+1) m+m, \\
w(t+3)=G(t+2) w(t+2)+m=G(t+2) G(t+1) G(t) w(t)+G(t+2) G(t+ \\
1) m+G(t+2) m+m, \\
\begin{array}{c}
w(t+4)= \\
G(t+3) w(t+3)+m=G(t+3) G(t+2) G(t+1) G(t) w(t)+ \\
G(t+3) G(t+2) G(t+1) m+G(t+3) G(t+2) m+m,
\end{array}
\end{gathered}
$$

Inductively, we obtain the explicit solution of (5) 


$$
w(t+k)=H(k, t) w(t)+F(k, t) m ; k \geq 1,
$$

where

$$
\begin{gathered}
H(0, t)=I \\
H(k, t)=\prod_{l=0}^{k-1} G(t+k-1-l) \\
=G(t+k-1) G(t+k-2) \cdots G(t+1) G(t) \\
F(k, t)=\sum_{l=0}^{k-1} H(j, t)
\end{gathered}
$$

and the initial condition $w(0)=\operatorname{vec}(W(0))$, where $W(0)$ is the matrix obtained from the initial data of each subpopulation that is computed in the next section.

Taking $t=0$ into (7) one gets the explicit expression of $w(k)$ in terms of the initial value matrix $W(0)$

$$
w(k)=H(k, 0) w(0)+F(k, 0) m .
$$

\subsection{Initial subpopulations}

The simulation results were computed from January $2016(t=0)$ to July 2020. The initial subpopulations were calculated according to several assumptions.

The total population in Spain [62] equal or older than 16 years $(39,129,371)$ is distributed according to age intervals $(j)$.

The initial populations of pathological shoppers per age are stated according to the literature.

By definition, rational consumers $\left(N_{j}\right)$ are those who follow a rational planned purchase behavior, including devoted religious people, people at risk of poverty, the long-term unemployed, and $50 \%$ of retired people.

Regarding religious people, $3.6 \%$ of the total population is considered to be devoted religious for $j=1,2$, and $8.3 \%$ and $29.1 \%$ are devoted religious for $j=3$ and $j=4$, respectively [69].

Long-term unemployed workers are defined as the unemployed who have been looking for a job for at least 12 months, have not worked during that period, and are taken as a percentage of the total working population. Note that half the unemployed in Spain are at risk of poverty [70]. As that proportion will form part of the poverty risk rate, only $50 \%$ of the long-term unemployed are included in $N_{j}$ to avoid double counting.

Thus rational consumers are estimated to be $N_{1,0}=1,600,827, N_{2,0}=1,913,703$, $N_{3,0}=6,688,474$ and $N_{4,0}=5,988,292$ in $t=0$. 
The prevalence of compulsive shoppers in college students and young people $(j=1)$ has been reported as the highest at around 20\% [64, 71]. In Spain, the prevalence of compulsive shopping has been estimated at $18.49 \%$ according to current VAT levels [68]. Among adults, the estimates of students with adult representative samples range from 3.4$8 \%[72,73]$. As age has been negatively and significantly associated with compulsive shopping [74], the lower and upper limits of the range are taken for $j=4$ and $j=3$, respectively.

Thus the percentages of pathological shoppers are estimated as follows: $A_{1,0}=0.1849$, $A_{2,0}=0.1849, A_{3,0}=0.08$ and $A_{4,0}=0.034$ in $t=0$.

The impulsive consumers $(S)$ in $t=0$ are calculated by the difference as $S_{j, t}=$ $B_{j, t}-N_{j, t}-A_{j, t}$, for each $j$.

Thus the matrix of consumers in $t=0$ is:

$$
W(0)=\left(\begin{array}{ccc}
1,600,827 & 2,138,373 & 848,213 \\
1,913,703 & 2,997,857 & 1,114,155 \\
6,688,474 & 11,581,381 & 1,588,683 \\
5,988,292 & 2,375,051 & 294,362
\end{array}\right)
$$

\section{Results}

\subsection{Economic scenarios}

The simulation results were computed from January 2016 to July 2020 . The poverty risk rate $\left(\right.$ Poverty $\left._{\text {rate }_{t}}\right)$ was quantified in January 2016 [62]. As of January 2017, the poverty risk rate changed. Such changes were proportionally distributed between July 2016 and January 2017. From January 2017, the poverty risk rate remained constant.

[Table 3 about here]

Thus the solution matrix in $t=9$ is:

$$
W(9)=\left(\begin{array}{ccc}
1,434,000 & 2,345,534 & 815,724 \\
1,413,006 & 3,101,861 & 984,464 \\
5,873,408 & 11,471,944 & 1,756,801 \\
5,270,376 & 2,022,882 & 407,677
\end{array}\right)
$$

[Figure 3 about here]

The impulsive buyers subpopulation increased from January 2016 to July 2020 for $j=$ $1,2,3$, while the subpopulation of impulsive consumers aged over 65 years $(j=4)$ slightly lowered (Table 3 ). 
The pathological consumers subpopulation underwent several variations depending on the age group ( $j$ ) from January 2016 to July of 2020 (Figure 3.c). For the buyers aged between 16 and 35 years $(j=1,2)$, the pathological consumers slightly reduced, but the pathological consumers increased for the shoppers aged more than 35 years $(j=3,4)$.

In order to estimate the short-term evolution of our subpopulations, we analyzed sensitivity to the economic scenario by considering the poverty risk rate a proxy of shopper's purchasing power. A different evolution of the poverty risk rate can be considered.

On the one hand, a recovery scenario poses a short-term situation for the improvement of the population's purchasing power and living conditions. This can be caused by a labor reform with a substantial increase in salaries and a reduction in temporality as a result of the Spanish government changing $[75,76]$. Examples of similar labor reforms can be found in France, Germany or Chile [77, 78].

On the other hand, and as far as we know, the current macroeconomic indicators in Spain are improving, but precarious workers also increase [79]. If a labor reform does not come into being that involves a real significant impact on wages and hiring conditions, temporary employment will increase and, consequently, so will the precariat. According to this assumption, the poverty risk rate will increase.

[Figure 4 about here]

The impulsive buyers subpopulation increased from January 2016 to July 2020 for the possible scenarios considered herein and for $j=1,2$ (Figure 4).

The pathological consumers subpopulation was less sensitive to the economic scenario. However, it underwent several variations depending on the age group $(j)$ from January 2016 to July of 2020, and increased for worsening scenarios. The pathological shoppers aged between 16 and 35 years $(j=1,2)$ slightly reduced for all the scenarios, but the pathological consumers increased for those aged over 35 years $(j=3,4)$.

As regards sensitivity to the economic scenario, for $j=1,2,3$ impulsive shoppers increased more in a recovery scenario (Figure 4.a, b and c). In a worsening scenario, the number of pathological buyers slightly increased, but also the increase in impulsive buyers smoothed.

Specifically, the impulsive consumers subpopulation aged over 65 years $(j=4)$ slightly lowered in the base scenario (unlike for $j=1,2,3$ ) and more notably so in worsening scenarios. The level of pathological consumers in July 2020 remained at $5.3 \%$ in all the scenarios for this age group.

\subsection{Sensitivity analysis}

A sensitivity analysis was performed for the coefficient of the retirement effect $(\propto)$. We changed the estimated value of $\propto$ to between 0.1 and 0.9 , and simulated the prevalence of the pathological consumers, but also that of the other two subpopulations, in line with the poverty risk rate for 2017 .

[Figure 5 about here] 
When we analyzed the total population of buyers in Spain, the subpopulations underwent variations below 5\% (Figure 5). We observed that for $0 \leq \propto \leq 1$, the subpopulation of $N$ oscillated within the $[35.1 \%, 39.9 \%]$ range, impulsive consumers $(S)$ moved within the $[54.2 \%, 49.4 \%]$ range and pathological consumers $(A)$ remained constant $(10.7 \%)$.

The specific results of shoppers older than 65 years $(j=4)$ showed for $0 \leq \propto \leq 1$, and the following results were obtained: the subpopulation of $N$ oscillated within the $[54.8 \%$, $77.9 \%$ ] range, impulsive consumers $(S)$ moved within the $[40.0 \%, 16.8 \%]$ range and pathological consumers $(A)$ remained constant $(5.3 \%)$. Note that to maintain the forecast decrease in $S_{4}, \propto$ could decrease only to 0.54 .

In addition, these results provided a measure of our model's robustness as the short-term simulations that predicted an increase in impulsive consumers in the total Spanish shoppers population were maintained for all the possible $\propto$ values ( $S$ was always higher than $48.8 \%$ ).

We perform additional sensitivity tests for Veblen $(V)$ and Pascal $(P)$ effects, both in transits from Ordinary $(N)$ to Impulsive $(S)$ and from Impulsive $(S)$ to Pathological $(A)$ shoppers and therapy recovery rate $(r)$. Parameters are simulated to move in the interval $[50 \%, 150 \%]$ of its estimated value.

Reported results (Table 4) do not vary substantially for the Total subpopulations of Ordinary $(N)$, Impulsive $(S)$ and Pathological shoppers (A) as compared to the estimated coefficients (Table 3) supporting the robustness of our model and the conclusions we draw.

[Table 4 about here]

\section{Conclusions}

In recent decades, interest in consumer misbehaviors has grown and consumer habits have recently changed with the use of technology and the Internet.

In this paper, we developed a behavioral mathematical bilateral matrix difference model that is transformable into a linear system of difference equations to model consumers' behavioral dynamics and to estimate the short-term evolution of different consumer subpopulations. The model can serve to design public health and education policies.

In our model, the transit of individuals among subpopulations is explained by diverse factors, such as hedonistic consumption, imitation or conspicuous consumption, the bandwagon effect, economy, and psychological, technological and demographic aspects.

The results show that total impulsive and pathological buyers will increase in all the economic scenarios. As regards differences between age groups, pathological consumers older than 35 years will increase slightly for all the considered scenarios, while pathological consumers aged between 16 and 35 years will slightly decrease in the three scenarios. Notable differences in the number of ordinary buyers are found for the group 
over 65 years. Moreover, the pathological consumers in July 2020 will remain at $5.3 \%$ in all the scenarios for this age group.

One of the potential utilities of this model is that the study can be extrapolated to other market economies where data are available, and it can take into account the peculiarities of each study area. The time period can be changed but, the longer it is, the less reliable it becomes. In addition, the model allows to simulate changes in the parameters. Specifically, a sensitivity analysis was performed for the coefficient of the retirement effect. The results predicted an increase in impulsive consumers in the total Spanish shoppers population maintained for all the possible values of the parameter and provided a measure of our model's robustness.

Note that, as in the literature, the difficulty of finding real data for Spain for some transit parameters meant that estimates had to be calculated according to some assumptions and hypotheses of human behavior simplification.

\section{References}

1. Reith G. Consumption and its discontents: addiction, identity and the problems of freedom, Brit J Sociol. 2004; 55(2):283-300.

2. Althofer J, Musgrove B. "A Ghost in Daylight" Drugs and the Horror of Modernity. Basingstoke, UK: Palgrave Communications; 2018, 4, 112.

3. Alter A. Irresistible. The Rise of Addictive Technology and the Business of Keeping Us Hooked. New York, USA: Penguin Random House, LLC; 2017.

4. Hunter KMB. Shopaholic stories: Tales of therapeutic addiction, governance, and political economy. J Consum Cult. 2018; 18(4):497-519.

5. Danziger PN. Shopping. Why we Love it and How Retailers can Create the Ultimate Customer Experience. USA: Kaplan Publishing; 2006.

6. Putoni S. Self-identity and purchase intention: an extension of the theory of planned behavior. Eur Adv Consum Res. 2001; 5:130-134.

7. Tsai WS, Yang Q, Liu Y. Young Chinese Consumers' Snob and Bandwagon Luxury Consumption Preferences. J Int Consum Mark. 2013; 25:290-304.

8. Lipovetsky G. La Felicidad Paradojica: Ensayo sobre la Sociedad de Hiperconsumo. Barcelona, Spain: Anagrama; 2010. (in Spanish).

9. Leibenstein H. Bandwagon, Snob, and Veblen effects in the theory of consumers' demand. Q J Econ. 1950; 64:183-207.

10. Pascal B. Pensées. Leon Brunschwig, eds. Paris, France: Garnier-Flammarion; 1976, 144, 334-97. (in French).

11. Ozen H, Engizek N. Shopping online without thinking: being emotional or rational? Asia Pac J Mark Logist. 2014; 26(1):78-93.

12. Lu J, Liu Z, Fang Z. Hedonic products for you, utilitarian products for me. Judgm Decis Mak. 2016; 11(4):332-341.

13. Freedman AM. Little wishes form the big dream. The American way of buying. Wall Street Journal. 1991; 4-10.

14. Ryabov I. Conspicuous consumption among Hispanics: Evidence from the Consumer Expenditure Survey. Res Soc Stratif Mobil. 2016; 44:68-76.

15. Damasio A. The Strange Order of Things. Life, Feelings, and the Making of Cultures. New York, USA: Pantheon Books; 2018. 
16. MacCluer CR. Industrial Mathematics, Modeling in Industry, Science and Government. Upper Saddle River, NJ: Prentice-Hall; 2000.

17. Girard R. Mimesis and Theory: Essays on Literature and Criticism, 19532005. Palo Alto, CA, USA: Stanford University Press; 2008.

18. Christakis NA, Fowler JH. Connected: the Surprising Power of Our Social Networks and How They Shape Our Lives. Boston, MA, USA: Little Brown and Company; 2009.

19. Raafat RM, Chater N, Frith C. Herding in Humans. Trends Cogn Sci. 2009; 13(10): 420-428.

20. Veblen T. The Theory of the Leisure Class. New York, USA: Macmillan; 1899.

21. Goldthorpe JH. Sociology as a Population Science. Cambridge, UK: Cambridge University Press; 2016.

22. Haddad WM, Chellaboina V, Nersesov SG. Hybrid nonnegative and compartmental dynamical systems. Math Probl Eng. 2002; 8(6):493-515.

23. García I, Jódar L, Merello P, Santonja FJ. A discrete mathematical model for addictive buying: Predicting the affected population evolution. Math Comput Model, 2011; 54(7-8):1634-1637.

24. Edman J, Berndt J. Oniomaniacs: the popular framing of consumption as a disease. Addict Res Theory. 2018; 26:431-438.

25. Kang LY. A study in compulsive buying behaviors and Internet addiction among e-commerce users between the ages of 20 30. Fam Environ Res, 2010; 48(1):67-81.

26. Currid-Halkett E. The Sum of Small Things. A Theory of Aspirational Class. New Jersey, USA: Princeton University Press; 2017.

27. Kurt D, Inman JJ, Gino F. Religious shoppers spend less money. J Exp Soc Psychol, 2018; 78:116-124.

28. Mihic M, Anic ID, Milakovic IK. Time spent shopping and consumer clothing purchasing behavior. Ekonomski Pregled. 2018; 69(2):89-105.

29. Camps V. El Gobierno de las Emociones. Barcelona, Spain: Herder; 2011. (In Spanish).

30. Michaud Y. El Nuevo Lujo: Experiencias, Arrogancia, Autenticidad. Barcelona, Spain: Taurus; 2015. (In Spanish).

31. Niesiobędzka M. An experimental study of the bandwagon effect in conspicuous consumption. Curr Issues Personal Psychol, 2018; 6(1):26-33.

32. De la Poza E, Guadalajara N, Jódar L, Merello P. Modeling Spanish anxiolytic consumption: Economic, demographic and behavioral influences. Math Comput Model 2013; 57(7-8):1619-1624.

33. Fischhoff B, Kadvany J. Risk. A Very Short Introduction. Oxford, UK: Oxford University Press; 2011.

34. Graham, A. Kronocker Products and Matrix Calculus: with Applications. New York, USA: John Wiley and Sons; 1981. a:22; b: 25; c:27.

35. Venn S, Burningham K, Christie I, Jackson T. Consumption junkies or sustainable consumers: considering the grocery shopping practices of those transitioning to retirement. Ageing Soc. 2017; 37(1):14-38.

36. Müller A, Mitchell JE, De Zwaan M. Compulsive buying. Am J Addiction. 2015; 24 (2):132-137. 
37. DeSarbo WS, Edwards EA. Typologies of compulsive buying behavior: A constrained clusterwise regression approach. J Consum Psychol. 1996; 5:231262.

38. Yi S. Heterogeneity of compulsive buyers based of impulsivity and compulsivity dimensions: A latent profile analytic approach. Psychiat Res. 2013; 208:174-182.

39. McElroy SL, Keck PE, Pope HG, Smith JM, Strakowski SM. Compulsive buying: A report of 20 cases. J Clin Psychiat. 1994; 55:242-248.

40. Schlosser S, Black DW, Repertinger S, Freet D. Compulsive buying. Demography, phenomenology, and comorbidity in 46 subjects. Gen Hosp Psychiat. 1994; 16:205-212.

41. Christenson GA, Faber RJ, de Zwaan M, Raymmond NC, Specker SM, Ekern MD, Mackenzie TB, Crosby RD, Crow SJ, Eckert ED. Compulsive buying: Descriptive characteristics and psychiatric comorbidity. J Clin Psychiat. 1994; 55:5-11.

42. Faber RJ, O'Guinn TC. A clinical screener for compulsive buying. J Consum Res. 1992; 19:459-469.

43. Ridgway NM, Kukar-Kinney M, Monroe KB. An expended conceptualization and a new measure of compulsive buying. J Consum Res. 2008; 35:622-639.

44. Belk RW. Third World Consumer Culture, Marketing and Development, Erdogan Kumuc and A. Fuat Firat, eds. Greenwich, CT: JAI; 1988,103-127..

45. Eastman JK, Goldsmith RE, Flynn LR. Status consumption in consumer behavior: Scale development and validation. JMTP. 1999; 7(3):41-52

46. Miller C. Luxury goods still have strong market despite new tax. Marketing News. 1991; 25(February 18): 1,6-7.

47. Darden WR, Reynolds FD. Shopping orientations and product usage rates. $J$ Market Res. 1971; 8(4):505-508.

48. Hoffman DL, Novak TP. Marketing in hypermedia computer-mediated environments: conceptual foundations. J Market. 1996; 60:50-68.

49. Babin BJ, Attaway JS. Atmospheric affect as a tool for creating value and gaining share of customer. J Bus Res. 2000; 49(2):91-99.

50. Klein JF, Falk T, Esch FR, Gloukhovtsev A. Linking pop-up brand stores to brand experience and word of mouth: The case of luxury retail. J Bus Res. 2016; 69(12):5761-5767.

51. Brooks S, Longstreet P, Califf C. Social media induced technostress and its impact on internet addiction: a distraction-conflict theory perspective. AIS Trans. Hum.-Comput. Interact. 2017; 9(2):99-122.

52. Qasem Z. Technostress Effect in Consumer Context: The Negative Effect of Following Social Media Influencers. In: Dwivedi Y., Ayaburi E., Boateng R., Effah J. (eds) ICT Unbounded, Social Impact of Bright ICT Adoption. TDIT 2019. IFIP Advances in Information and Communication Technology, Springer, Cham, 2019; vol 558.

53. Germano R. Outsourcing welfare: How the money immigrants send home contributes to stability in developing countries. Oxford Scholarship Online, 2018.

54. Cancian S, Wegge SA. 'If it is not too expensive, then you can send me sugar': money matters among migrants and their families. Hist Fam., 2016; 21 (3): 350-367. 
55. Bilgili Ö. Economic Integration to Send Money Back Home? J Immigr Refugee Stud., 2015; 13 (4): 379-400.

56. Essoo N, Dibb, S. Religious influences on shopping behaviour: An exploratory study. J Market Manag. 2010; 20(7-8):683-712.

57. Hamin H, Tung RL, Baumann C, Hoadley S. Customers' savings rate and share of wallet: the moderating role of religion and ethnicity/immigrant generation vis-à-vis attitude as mediator. $J$ Strat Mar., 2018; 26 (5): 400-416.

58. Baumann D, Ruch W, Margelisch K, Gander F, Wagner L. Character Strengths and Life Satisfaction in Later Life: an Analysis of Different Living Conditions. Appl Res Qual Life., 2019, Article in Press.

59. Diario de Leon. Pensión, soledad y salud acaparan la preocupación de los jubilados.

Available

at:

http://www.diariodeleon.es/noticias/sociedad/pension-soledad-saludacaparan-preocupacion-jubilados_65124.html (Accessed 21.09.2018) (In Spanish).

60. Vida Caixa. (2017). Barometer Vida Caixa. Portrait of a Spanish retiree. Available at:

https://www.vidacaixa.es/documents/51066/151087/conclusiones-barometrovidacaixa-retrato-del-jubilado.pdf/641c7683-4ae7-0d01-bdf6-797947d88ef7 (Accessed 21.09.2018) (In Spanish).

61. Banco Interamericano de Desarrollo. Remesas e inclusión financiera. (2016). Available at:

https://publications.iadb.org/bitstream/handle/11319/7894/Remesas-einclusion-financiera-Analisis-de-una-encuesta-de-migrantes-de-AmericaLatina-y-el-Caribe-en-Espana.pdf?sequence=1 (Accessed 07.12.2018) (In Spanish)

62. Spanish Institute of Statistics. Available at: http://www.ine.es (Accessed 21.09.2018)

63. Palma MA, Ness ML, Anderson DP. Fashionable food: a latent class analysis of social status in food purchases. Appl Econ. 2017; 49(3):238-250

64. Harnish RJ, Bridges KR, Karelitz JL. Compulsive buying: Prevalence, irrational beliefs and purchasing. Int J Ment Health Addict. 2017; 15(5):9931007.

65. Lam LT, Lam MK. The association between financial literacy and Problematic Internet Shopping in a multinational sample. Addict Behav Rep. 2017; 6:123127.

66. Montesó-Curtoa P, Aguilar-Martín C. Depression according to age and gender: An analysis in a community. Aten Primaria. 2014; 46:167-168.

67. Generalitat Valenciana. Prevalencia de ansiedad y depresión en Valencia publicados en la Memoria de Salud de 2016. Available at: http://www.san.gva.es/web/comunicacion/memoria-2016 $\quad$ (Accessed 05.01.2019) (In Spanish).

68. De la Poza E, Garcia I, Jodar L, Merello, P. Does VAT growth impact compulsive shopping in Spain? In Cortes JC, Jódar L, Villanueva RJ. eds. Mathematical modeling in social sciences and engineering, New York, USA: Nova science Publishers, Inc.; 2014.

69. Center for Sociological Research. Encuesta sobre religiosidad. Available at: http://www.cis.es/cis/export/sites/default/- 
Archivos/Marginales/2740 2759/2752/Cru275200EDAD.html (Accessed 05.01.2019) (In Spanish).

70. Eurostat, Indicator at-risk of poverty rate of unemployed persons. Available at:

https://ec.europa.eu/eurostat/tgm/table.do?tab=table\&init=1\&language=en\& pcode $=$ tesem $210 \&$ plugin $=1$ (Accessed 05.01.2019)

71. MacLaren VV, Best LA. Multiple addictive behaviors in young adults: Student norms for the shorter PROMIS questionnaire. Addict Behav. 2010; 35(3):252-255.

72. Maraz A, Griffiths MD, Demetrovics Z. The prevalence of compulsive buying: a meta-analysis. Addict. 2016; 111(3):408-419

73. Koran LM, Faber RJ, Aboujaoude E, Large MD, Serpe RT. Estimated prevalence of compulsive buying behavior in the United States. Am J Psychiat. 2006; 163 (10):1806-1812.

74. Black DW. Compulsive buying disorder: a review of the evidence. CNS Spectr. 2007; 12(2):124-132.

75. La Vanguardia. Patronal y sindicatos ultiman el acuerdo de subida salarial para los próximos años. Available at:

http://www.lavanguardia.com/economia/20180608/444212364382/patronalsindicatos-subida-salarios.html (Accessed 05.01.2019) (In Spanish).

76. El Mundo. El Gobierno retrasa al próximo jueves la entrada en vigor del aumento del permiso de paternidad, la subida de las pensiones y la rebaja del IVA en el cine. Available at:

http://www.elmundo.es/economia/macroeconomia/2018/07/02/5b3a4962468 aeb01088b468e.html (Accessed 05.01.2019) (In Spanish).

77. Gouvernement. Labour Law Reform. Available at: https://www.gouvernement.fr/en/labour-law-reform (Accessed 14.11.2018).

78. Todolí-Signes A. El Bonus Salarial. Valencia, Spain: Tirant lo Blanch, 2017. (In Spanish).

79. Standing G. The Precariat: The New Dangerous Class. New York, USA: Bloomsbury Academic, 2011. 
Table 1. Estimation of parameters and absolute demographic balance for each $t$.

\begin{tabular}{|c|c|c|c|c|}
\hline & $j=1$ & $j=2$ & $j=3$ & $j=4$ \\
\hline$\sigma$ & 0.0055 & & & \\
\hline$d_{j}$ & 0.00011 & 0.00018 & 0.00149 & 0.05128 \\
\hline$i_{j}$ & 17,370 & 2,659 & $-7,915$ & -147 \\
\hline$\propto$ & & & & 0.59 \\
\hline Total Population & \multicolumn{4}{|c|}{$39,129,371$} \\
\hline \multicolumn{5}{|l|}{ Demographic balance } \\
\hline$N$ & 87,214 & 1,498 & $-15,519$ & $-307,206$ \\
\hline$S$ & 103,696 & 56 & $-19,333$ & $-121,811$ \\
\hline$A$ & 41,167 & 21 & $-2,652$ & $-15,097$ \\
\hline
\end{tabular}


Table 2. Poverty risk rates

\begin{tabular}{|l|l|l|l|l|}
\hline & $j=1$ & $j=2$ & $j=3$ & $j=4$ \\
\hline$t=0$ & 0.296 & 0.246 & 0.217 & 0.130 \\
\hline$t=2$ & 0.285 & 0.232 & 0.203 & 0.148 \\
\hline
\end{tabular}


Table 3. Results (as percentages) for January 2016 and July 2020 according to the current economic situation (base scenario).

\begin{tabular}{|l|l|r|c|c|c|}
\hline & Age group $(j)$ & $B$ (total shoppers) & $N$ & $S$ & $A$ \\
\hline \multirow{5}{*}{ January 2016 } & $16-25$ & $11.7 \%$ & $34.9 \%$ & $46.6 \%$ & $18.5 \%$ \\
\cline { 2 - 6 } & $26-35$ & $15.4 \%$ & $31.8 \%$ & $49.8 \%$ & $18.5 \%$ \\
\cline { 2 - 6 } & $36-64$ & $50.8 \%$ & $33.7 \%$ & $58.3 \%$ & $8.0 \%$ \\
\cline { 2 - 6 } & 65 and more & $22.1 \%$ & $69.2 \%$ & $27.4 \%$ & $3.4 \%$ \\
\cline { 2 - 6 } & Total & $100.0 \%$ & $41.4 \%$ & $48.8 \%$ & $9.8 \%$ \\
\hline \multirow{5}{*}{ July 2020 } & $16-25$ & $12.5 \%$ & $31.2 \%$ & $51.0 \%$ & $17.8 \%$ \\
\cline { 2 - 6 } & $26-35$ & $14.9 \%$ & $25.7 \%$ & $56.4 \%$ & $17.9 \%$ \\
\cline { 2 - 6 } & $36-64$ & $51.8 \%$ & $30.7 \%$ & $60.1 \%$ & $9.2 \%$ \\
\cline { 2 - 6 } & 65 and more & $20.9 \%$ & $68.4 \%$ & $26.3 \%$ & $5.3 \%$ \\
\cline { 2 - 6 } & Total & $100.0 \%$ & $37.9 \%$ & $51.3 \%$ & $10.7 \%$ \\
\hline
\end{tabular}


Table 4. Sensitivity analysis of Veblen (V), Pascal (P) and recovery rate (r) parameters. Subpopulations results for July 2020 according to the current economic situation (base scenario).

\begin{tabular}{|l|l|r|r|r|r|r|r|}
\hline & & \multicolumn{5}{|c|}{ Parameter } \\
\hline & & \multicolumn{2}{|c|}{$\boldsymbol{V}$} & \multicolumn{2}{|c|}{$\boldsymbol{P}$} & \multicolumn{2}{c|}{$\boldsymbol{r}$} \\
\hline Subpopulation & & 0,0463 & 0,1389 & 0,2500 & 0,7500 & 0,0018 & 0,0053 \\
\hline $\mathbf{N}$ & $16-25$ & $31,5 \%$ & $30,8 \%$ & $31,3 \%$ & $31,1 \%$ & $30,9 \%$ & $31,4 \%$ \\
\hline & $26-35$ & $26,1 \%$ & $25,1 \%$ & $25,8 \%$ & $25,6 \%$ & $25,4 \%$ & $25,9 \%$ \\
\hline & $36-64$ & $30,9 \%$ & $30,5 \%$ & $30,9 \%$ & $30,6 \%$ & $30,5 \%$ & $30,8 \%$ \\
\hline & 65 and more & $68,6 \%$ & $68,5 \%$ & $68,1 \%$ & $68,7 \%$ & $68,4 \%$ & $68,6 \%$ \\
\hline & Total & $38,1 \%$ & $37,7 \%$ & $38,0 \%$ & $37,9 \%$ & $37,7 \%$ & $38,0 \%$ \\
\hline $\mathbf{S}$ & $16-25$ & $50,7 \%$ & $51,4 \%$ & $51,0 \%$ & $51,1 \%$ & $51,0 \%$ & $51,1 \%$ \\
\hline & $26-35$ & $55,9 \%$ & $57,0 \%$ & $56,3 \%$ & $56,5 \%$ & $56,4 \%$ & $56,5 \%$ \\
\hline & $36-64$ & $59,9 \%$ & $60,3 \%$ & $60,0 \%$ & $60,1 \%$ & $60,1 \%$ & $60,1 \%$ \\
\hline & 65 and more & $26,1 \%$ & $26,2 \%$ & $26,6 \%$ & $25,9 \%$ & $26,2 \%$ & $26,2 \%$ \\
\hline A & Total & $51,1 \%$ & $51,6 \%$ & $51,3 \%$ & $51,3 \%$ & $51,3 \%$ & $51,4 \%$ \\
\hline & $16-25$ & $17,7 \%$ & $17,8 \%$ & $17,7 \%$ & $17,8 \%$ & $18,0 \%$ & $17,6 \%$ \\
\hline & $26-35$ & $17,9 \%$ & $17,9 \%$ & $17,9 \%$ & $17,9 \%$ & $18,2 \%$ & $17,7 \%$ \\
\hline & $36-64$ & $9,2 \%$ & $9,2 \%$ & $9,1 \%$ & $9,3 \%$ & $9,4 \%$ & $9,1 \%$ \\
\hline & 65 and more & $5,3 \%$ & $5,3 \%$ & $5,3 \%$ & $5,3 \%$ & $5,4 \%$ & $5,2 \%$ \\
\hline & Total & $10,7 \%$ & $10,8 \%$ & $10,7 \%$ & $10,8 \%$ & $10,9 \%$ & $10,6 \%$ \\
\hline
\end{tabular}


Figure 1. Block diagram of consumers' behavioral transits among subpopulations.

Figure 2. Block diagram of demographic transits.

Figure 3. Dynamic evolution of the three subpopulations for each $j$ by considering a constant poverty risk rate since 2017 for a) ordinary shoppers, b) impulsive shoppers, c) pathological shoppers. Dashed line: $j=1$, gray solid line: $j=2$, dotted line: $j=3$, black solid line: $j=4$.

Figure 4. Sensitivity to the poverty risk rate. The three subpopulations are computed for $t=9$ by considering different poverty risk rates in $t=9$, for a) $j=1$, b) $j=2$, c) $j=$ 3, d) $j=4$. Dashed line: ordinary shoppers, dotted line: impulsive shoppers, solid line: pathological shoppers.

Figure 5. a) Population aged 65 and more as percentages. b) All the consumer populations as percentages. Dashed line: ordinary buyers, solid line: impulsive buyers, horizontal axis: $\propto$ values, data simulated for July 2020 . 